\title{
Investigating the stress effects on Fexofenadine hydrochloride and Montelukast sodium in bulk and tablet dosage form using a validated LC-DAD method
}

\author{
C.N. Nalini ${ }^{1 *}$, G. Vinoth ${ }^{1}$, P. Guganathan ${ }^{1}$ \\ 1 Department of Pharmaceutical Analysis, C.L. Baid Metha College of Pharmacy, Chennai-97.
}

\begin{abstract}
The main aim was to develop RP-HPLC method for the simultaneous estimation of Fexofenadine hydrochloride and Montelukast sodium in tablet dosage form. A mobile phase comprising solvent $\mathrm{A}$ as $0.1 \% \mathrm{v} / \mathrm{v}$ trifluoroacetic acid in water and solvent $\mathrm{B}$ as acetonitrile with methanol in the ratio of $2: 3 \% \mathrm{v} / \mathrm{v}$ was used and the flow was set in a gradient mode with a stationary phase of phenyl-hexyl silica column $(150 \times 4.6 \mathrm{~mm}, 5 \mu$ i.d).The detection wavelength is $254 \mathrm{~nm}$ using PDA detector. The method was validated according to ICH parameters. The results denote that the method is linear and within the range of $60-180 \mu \mathrm{g} / \mathrm{ml}$ for Fexofenadine and 5-15 $\mu \mathrm{g} /$ $\mathrm{ml}$ for Montelukast with the r2 of 0.9998 and 0.9999 respectively. The degradants peaks non-interfered with main peaks. The developed method is acceptable for the determination of Fexofenadine and Montelukast in routine analysis of dosage form.
\end{abstract}

Keywords: FEX-Fexofenadine hydrochloride, MON- Montelukast sodium, Coelution, forced degradation, Gradient elution.

\section{INTRODUCTION}

Fexofenadine hydrochloride (FEX) is chemically 2-[4-[1-hydroxy-4-[4-hydroxy (diphenyl) methyl] piperidin-1-yl] butyl] phenyl]-2-methylpropanoic acid (figure 1) with amolecular mass of $501.68 \mathrm{~g} / \mathrm{mol}$ and $\log \mathrm{P}$ value of $2.81 .^{1}$ It is an second generation antihistaminic agent used for the symptomatic relief of nasal

\footnotetext{
${ }^{*}$ Correspondence:

C. N. Nalini, Professor and Head,Department of Pharmaceutical Analysis,C. L. Baid Metha College of Pharmacy,

Chennai-97, India,Email: nalini_cn@yahoo.co.in

ORCIDs:

CN Nalini: 0000-0002-3960-3154

G Vinoth: 0000-0002-4979-2665

P Guganathan: 0000-0002-2508-3741

(Received 03 October 2020, accepted 17 June 2020)
} 
congestion, itching, management and treatment of diseases like chronic urticaria and allergic rhinitis ${ }^{-2,3}$

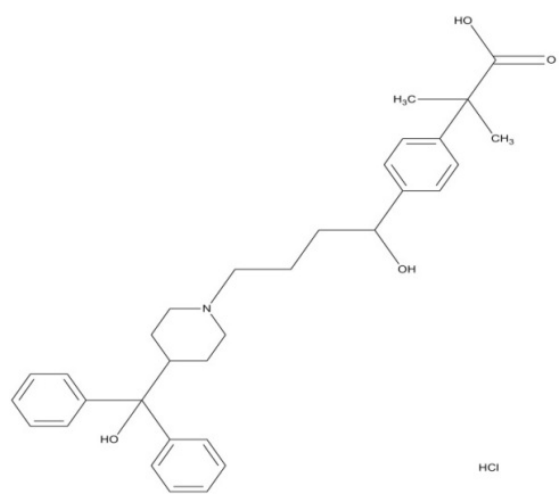

Figure 1. Structure of Fexofenadine hydrochloride

Montelukast sodium (MON) is chemically 2-[1-[[(1R)-1-[3-[(E)-2-(7-chloroquinolin-2-yl) ethenyl] phenyl]-3-[2-(2-hydroxypropan-2yl) phenyl] propyl] sulfanylmethyl] cyclopropyl] acetic acid (figure 2) with a molecular weight of 586.187 $\mathrm{g} / \mathrm{mol}$ and $\log \mathrm{P}$ value of $7.9^{4}$. It is an anti-asthmatic agent and cysteinyl leukotriene receptor antagonist which slackens the inflammation mediating action exerted by immune system and averts broncho constriction as well asinflammation in respiratory diseases ${ }^{5}$. FEX and MON in combined tablet dosage form areused for the treatment of tenacious allergic rhinitis, prurigo nodularis and pemphigoid nodularis. Fexofenadine is a non-sedating agent possessing inflammatory mediating action like MON. Both the drugs in concomitant dosage for mareused in the treatment of allergic reactions and inflammatory mediating actions ${ }^{6}$.

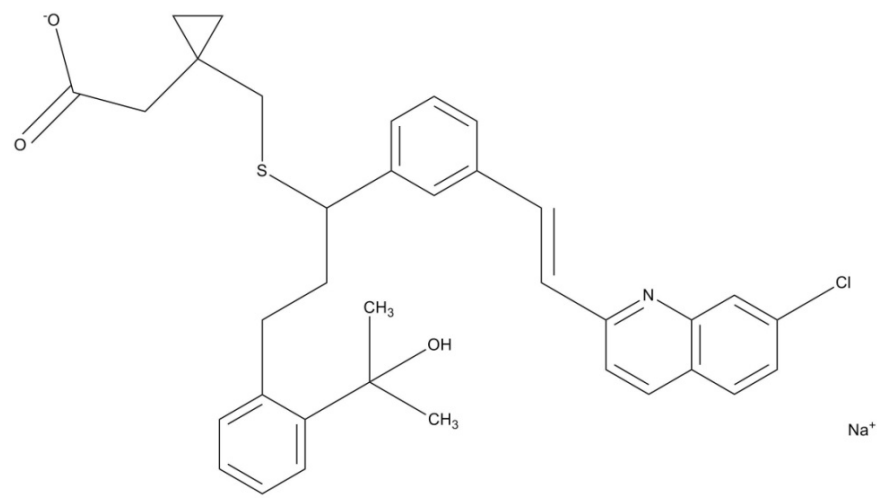

Figure 2. Structure of Montelukast sodium 
A number of researchers have reported various analytical techniques for the determination of FEX and MON either alone or in combination from different matrices. These methods include electrometric titration ${ }^{7,8}$,spectrometric methods such as colorimetry ${ }^{8-13}$, UV-spectrometry ${ }^{14-22}$,spectrofluorimetry ${ }^{23-25}$,chromatographic techniques like Thin Layer Chromatography ${ }^{26}$,High Performance Thin Layer Chromatography ${ }^{27,28}$, High Performance Liquid Chromatography ${ }^{22,29-56}$,Ultra Pressurized Liquid Chromatography ${ }^{57,58}$,Hyphenated techniques such as Liquid chromatography- mass spectrometry ${ }^{59-63}$ and capillary electrophoresis ${ }^{62}$.Official HPLC methods are available for both the drugs individually in USP ${ }^{63}$, 64. Application of reported USP monograph method of Fexofenadine for the simultaneous estimation of FEX and MON fetched no peak for MON. Alternatively application of official USP method of MON for the determination of two drugs simultaneously resulted inpoor separation of two peaks. Reported stability indicating assay methods for simultaneous estimation of two drugs by HPLC ${ }^{33-37}$ using $\mathrm{C}_{18}$ and $\mathrm{C}_{8}$ analytical column, present the main peaks very near to the dead volume and the separation of degradants peaks were not clear due to co-elution with the main peaks.

In our present work, an ion pair agent was used in HPLC stability indicating assay to get good peak shapes. Reported stability indicating methods make use of $\mathrm{C}_{18} / \mathrm{C}_{8}$ column for the separation of two drugs where there are hydrogen bond interactions. Comparatively in our method phenyl-hexyls silica column ${ }^{65} \mathrm{was}$ used which exhibited both hydrogen bond as well as aromatic interactions. In order to obtain the complete separation of degradants peak from the significant main peaks the retention time values of both the analytes should be well separated so that there may not be overlapping of peaks. Also the gradient mode of separation prevents co-elution of degradants with the main peaks. Based on the $\log \mathrm{P}$ values (non-polar) of both the drugs, it can be predicted that usage of more organic modifiers will result in poor resolution leading to the concurrent elution of the degradants along with the main peaks ${ }^{66}$. The developed method was validated according to ICH guidelines with the parameters like accuracy, linearity, precision, robustness, specificity, system suitability, etc. ${ }^{67}$

\section{METHODOLOGY}

\section{Chemicals and Reagents.}

Methanol (HPLC grade obtained from Finar, Mumbai, India), Acetonitrile (HPLC grade obtained from Finar, Mumbai, India), Trifluoroacetic acid, Sodium hydroxide, 30\% Hydrogen peroxide, Hydrochloric acid (Analytical Reagent grade obtained from Rankem, Mumbai, India) and Milli Q water as double distilled water and membrane filters $0.45 \mu \mathrm{m}$ as membrane filters from Millipores Ltd, Banglore, India. 


\section{Instruments and Software}

Chromatography study was performed in Empower software with Waters 2695 separations module with Photodiode array detector 2996 with a quaternary pump and autosampler injections. Separation was carried out using Phenonomenex, Phenyl-hexyl silyl column ( $150 \times 4.6 \mathrm{~mm}$, Luna $5 \mu$ i.d.) obtained fromHyderabad, India. Analytical balance (semi-micro) Shimadzu AUW220D from Chennai, India. Ultrasonicator (LMUC-12) Spectrum tek from Chennai, India, Digital pH meter (PH12-5p-920) spectrum tek from, Hot air oven from Inlab equipment Pvt. Ltd. from Chennai, India.

\section{Methods}

\section{Pure Standards}

FEX and MON were obtained from Vital laboratories Pvt. Ltd, Gujarat, India with percentage purity of 99.07\% (CAS No-153439-40-8) and 98.12\% (CAS No 151767-02-1) respectively.

\section{Pharmaceutical Formulation}

Generic tablets of FEX (120 mg) and MON(10 mg) were obtained from the manufacturer Saimirra innopharm Pvt. Ltd., Chennai, India

\section{Preparation of stock and working solutions}

A stock solution of FEX (1.2 mg/ml) and MON (0.1 mg/ml) was prepared by accurately weighing $120.0 \mathrm{mg}$ of FEX and 10.0 mg of MONusing Methanol: water (3:1) as diluent. Working standard solution was prepared in the concentration of $\operatorname{FEX}(120 \mu \mathrm{g} / \mathrm{ml})$ and MON $(10 \mu \mathrm{g} / \mathrm{ml})$.

\section{Chromatographic conditions}

Chromatographic separation was carried out using (Phenomenex) Phenylhexyl silyl column $(150 \times 4.6 \mathrm{~mm}$, Luna $5 \mu$ i.d. $)$ in gradient mode. The mobile phase used was Solvent A: $0.1 \% \mathrm{v} / \mathrm{v}$ trifluoroacetic acid in water and solvent B: Acetonitrile: Methanol (2:3). Flow rate of $1.5 \mathrm{ml} / \mathrm{min}$ was maintained with an injection volume of $15 \mu \mathrm{l}$ and thedetection was set at $254 \mathrm{~nm}$ using PDA detector. Prepared mobile phase was filtered using $0.45 \mu \mathrm{m}$ Milli pore membrane filter. Total run time is $\mathbf{2 2 . 0} \mathrm{min}$, where the gradient elution is maintained ato5 mins solvent $\mathrm{A}$ is $48 \%$ and solvent $\mathrm{B}$ is $52 \%$, at $10-17 \mathrm{mins}$ solvent $\mathrm{A}$ is $35 \%$ and solvent $\mathrm{B}$ is $65 \%$ and after 20 min the gradient comes back to initial condition. Chromatographic separation was carried out in ambient condition. 


\section{Calibration curve}

From the stock solution, serial dilutions were made to prepare working standard solutions of FEX and MON in the concentration range of $60-180 \mu \mathrm{g} / \mathrm{ml}$ and $5^{-15} \mu \mathrm{g} / \mathrm{ml}$ respectively. A calibration curve is constructed with area versus concentration in microgram $/ \mathrm{ml}$.

\section{Preparation of Sample Solution}

Twenty tablets were finely powdered and sample solutions were prepared by accurately weighing a weight equivalent to $120 \mathrm{mg}$ of FEX and $10 \mathrm{mg}$ of MON and further dilutions were made to give concentration of $120 \mu \mathrm{g} / \mathrm{ml}$ and $10 \mu \mathrm{g} /$ $\mathrm{ml}$ respectively.

\section{Forced Degradation Studies}

Forced degradation is stress testing and the dosage form is subjected to forced degradation using accelerated environmental conditions. Various impurities which arise during the storage of drug products in different environmental conditions can be studied using these stress studies. It also helps to calculate the inherent stability of the molecule, to determine the degradation pathways and endorses the stability indicating assay ${ }^{67}$. In this study the combined dosage form of FEX and MONwas exposed to degradation studies like acid hydrolysis, alkaline hydrolysis, thermal degradation, oxidative degradation and photolytic degradation

Acid hydrolysis

Acid hydrolysis was carried out in $807 \mathrm{mg}$ of powdered tablet which is treated with $5 \mathrm{ml}$ of $0.1 \mathrm{~N}$ hydrochloric acid in a $100 \mathrm{ml}$ volumetric flask. The volumetric flask was heated on a water bath at $60^{\circ} \mathrm{c}$ for 2 hours and allowed to cool. Neutralized the solution with $5 \mathrm{ml}$ of $0.1 \mathrm{~N}$ sodium hydroxide and diluted the volume with diluent. Final solution was made up to the concentration of FEX $(120 \mu \mathrm{g} / \mathrm{ml})$ and $\mathrm{MON}(10 \mu \mathrm{g} / \mathrm{ml})$ with diluent.

\section{Alkaline hydrolysis}

Accurately weighed $807 \mathrm{mg}$ of powdered tablet and transferred to a $100 \mathrm{ml}$ volumetric flask to which $5 \mathrm{ml}$ of $0.1 \mathrm{~N}$ sodium hydroxidewas added. The flask was heated on a water bath at $60^{\circ} \mathrm{c}$ for 2 hours and allowed to cool. Neutralization was carried out using $5 \mathrm{ml}$ of $0.1 \mathrm{~N}$ hydrochloric acid andmade up to volume with diluent to give a final concentration of FEX $(120 \mu \mathrm{g} / \mathrm{ml})$ and MON $(10 \mu \mathrm{g} / \mathrm{ml})$.

\section{Thermal degradation}

Accurately weighed $807 \mathrm{mg}$ of powdered tablet and it was exposed to $105^{\circ} \mathrm{c}$ for 
2 hours in hot air oven. Sample was allowed to cool and transferred to $100 \mathrm{ml}$ of volumetric flask, the volume was made up with thediluent to give a concentration of FEX $(120 \mu \mathrm{g} / \mathrm{ml})$ and MON $(10 \mu \mathrm{g} / \mathrm{ml})$.

\section{Oxidative degradation}

Oxidative degradation was carried out using $5 \mathrm{ml}$ of $30 \%$ hydrogen peroxide $\left(\mathrm{H}_{2} \mathrm{O}_{2}\right)$ to $807 \mathrm{mg}$ of sample in $100 \mathrm{ml}$ volumetric flask. Heated the flask on water bath for 2 hours at $60^{\circ} \mathrm{c}$ and allowed to cool. Final concentration of FEX $(120 \mu \mathrm{g} / \mathrm{ml})$ and MON $(1 \mathrm{O} \mu \mathrm{g} / \mathrm{ml})$ were prepared with diluent.

\section{Photolytic degradation}

Accurately weighed $807 \mathrm{mg}$ of powdered tablet sampleand it wasexposed to sunlight for 2 hours, allowed to cool and transferred to volumetric flask. The final solution was made up with diluentto give a concentration of FEX $(120 \mu \mathrm{g} /$ $\mathrm{ml})$ and $\mathrm{MON}(1 \mathrm{O} \mu \mathrm{g} / \mathrm{ml})$.

All the prepared solutions were injected in chromatographic system and the chromatograms were recorded for degradation studies.

\section{RESULTS and DISCUSSION}

\section{Method development}

Chromatographic conditions such as analytical column, mobile phase, flow rate, column temperature, sample temperature, detection wavelength were optimized for better separation of main peaks with degradants peaks.

Various mobile phase compositions, detection wavelength and analytical column from the reported methods ${ }^{33-37}$ and official monograph methods ${ }^{63,64}$ were tried during method development. While trying thefirst two reported methods with mobile phase composition of Phosphate buffer pH 6.0: Methanol (25:75) and $0.1 \%$ Triethylamine: Acetonitrile (30:70), good peak shape was obtained in both the methods butthe resolution factor and plate countwere less showing non-compliant intermediate precision. Third trial was with mobile phase ratio of ortho phosphoric acid and methanol (40:60) using $\mathrm{C}_{8}$ analytical column, which yield eda poor resolution where there is a possibility of overlapping of degradants peak with that of analytes. After several trials, the chromatographic conditions were optimized as given and used in gradient mode: the mobile phase - $0.1 \%$ trifluoroacetic acid in water (Solvent A), acetonitrile with methanol (2:3) (Solvent B). FEX is less non-polar than the MON, so between o-5 min Fexofenadine got eluted from the column and in 5-17 min MONgot eluted due to increased non-polarity in mobile phase. Gradient mode was followed for the better separation of two peaks, so that the degradants peak can be well defined 
by avoiding co-elution in forced degradation assay. The detection wavelength was set by isobestic point of two drug molecules in UV spectroscopy. The results of quantitative estimation are given in Table1 and \%RSD was less than $2 \%$. The standard chromatogram is shown in the figure 3 .

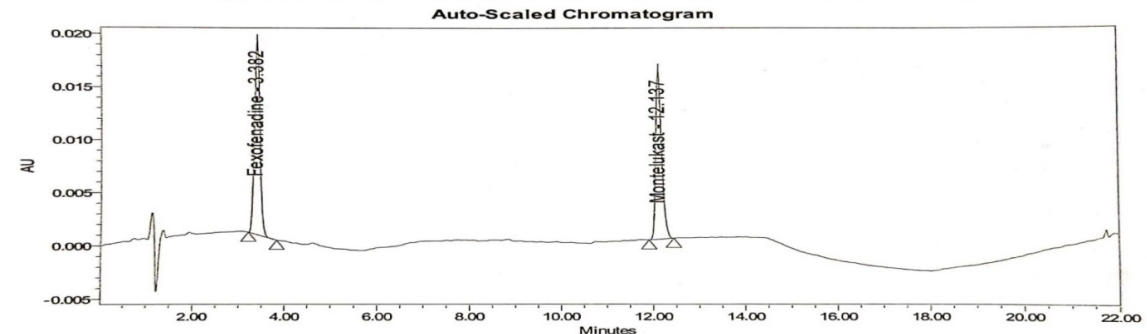

Figure 3.Chromatogram of $100 \%$ concentration of $(120 \mu \mathrm{g} / \mathrm{ml})$ Fexofenadine hydrochloride and $(10 \mu \mathrm{g} / \mathrm{ml})$ Montelukast sodium.

Table 1. Quantitative estimation of FEX and MON.

\begin{tabular}{|c|c|c|c|c|c|}
\hline \multirow{2}{*}{ S.No } & \multirow{2}{*}{ Sample Name } & \multicolumn{2}{|c|}{ Retention Time } & \multicolumn{2}{c|}{ Amount present (\%) } \\
\hline & & FEX & MON & FEX & MON \\
\hline $\mathbf{1}$ & Standard & 3.338 & 12.048 & 110.31 & 101.11 \\
\hline $\mathbf{2}$ & Sample 1 & 3.332 & 12.056 & 98.25 & 99.31 \\
\hline $\mathbf{3}$ & Sample 2 & 3.334 & 12.045 & 99.56 & 100.31 \\
\hline
\end{tabular}

\section{Validation of the Method}

The developed method was validated according to ICH guidelines ${ }^{68}$.

\section{System suitability}

System suitability was carried out by injecting six replicates of standard solution containing $120 \mu \mathrm{g} / \mathrm{ml}$ of FEX and $10 \mu \mathrm{g} / \mathrm{ml}$ of MON. The parameters like retention time $\left(\mathrm{t}_{\mathrm{R}}\right)$, theoretical plates $(\mathrm{N})$ and peak reproducibility are reported in Table 2.

Table 2. System suitability parameters for FEX and MON.

\begin{tabular}{|c|c|c|}
\hline \multirow{2}{*}{ Parameter } & \multicolumn{2}{|c|}{ Response } \\
\cline { 2 - 3 } & FEX & MON \\
\hline$t_{\mathrm{R}}(\min ) \&(\mathbf{R S D} \%)$ & $3.290 \&(0.08)$ & $12.006 \&(0.05)$ \\
\hline Theoretical plates & 3894 & 42733 \\
\hline Tailing factor & 1.30 & 1.20 \\
\hline
\end{tabular}




\section{Linearity\& Range}

Determination of linearity of the method was executed by plotting the calibration curve of peak area versus the concentration range of $60-180 \mu \mathrm{g} / \mathrm{ml} \mathrm{FEX}$ and 5-15 $\mu \mathrm{g} / \mathrm{ml} \mathrm{MON}$. Result of linearity was statistically examined by correlation coefficient, slope of the regression line and $y$ - intercept. The data are presented in Table 3.

Table 3. Calibration data for FEX and MON.

\begin{tabular}{|c|c|c|}
\hline \multirow{2}{*}{ Parameters } & \multicolumn{2}{|c|}{ Response } \\
\cline { 2 - 3 } & FEX & MON \\
\hline Range & $60.00-180.00 \mu \mathrm{g} / \mathrm{ml}$ & $5.00-15.00 \mu \mathrm{g} / \mathrm{ml}$ \\
\hline Slope & 12419.70 & 144000.00 \\
\hline Intercept & 670.68 & 121.30 \\
\hline $\mathbf{y}$-intercept & 0.45 & 0.08 \\
\hline $\mathbf{R}^{2}$ & 0.9998 & 0.9999 \\
\hline
\end{tabular}

\section{Accuracy}

Accuracy of the method was determined by preparing three known concentrations of FEX and MON comprising6o \& $5 \mu \mathrm{g} / \mathrm{ml}, 120 \& 10 \mu \mathrm{g} / \mathrm{ml}$ and 180 \& $15 \mu \mathrm{g} / \mathrm{ml}$ respectively representing $50 \%, 100 \%$ and $150 \%$ of working standard solution. Prepared solutions were injected into HPLC in triplicate manner and the results are reported in Table4. Results show that relative standard deviation (\%RSD) was found to be less than 2.

Table 4. Accuracy of the proposed method at three different concentrations of FEX and MON.

\begin{tabular}{|c|c|c|c|c|c|c|c|c|}
\hline \multirow[t]{2}{*}{ Concentration \% } & \multicolumn{2}{|c|}{ Amount added (mg) } & \multicolumn{2}{|c|}{ Amount found (mg) } & \multicolumn{2}{|c|}{ Recovery (\%) } & \multicolumn{2}{|c|}{$\begin{array}{l}\text { Mean \% Recovery } \\
\text { (\%RSD) }\end{array}$} \\
\hline & FEX & MON & FEX & MON & FEX & MON & FEX & MON \\
\hline \multirow{3}{*}{$50 \%$} & 0.060 & 0.005 & 0.059 & 0.005 & 98.33 & 100.23 & \multirow{3}{*}{$\begin{array}{l}98.32 \% \\
(0.03 \%)\end{array}$} & \multirow{3}{*}{$\begin{array}{l}102.75 \% \\
(1.73 \%)\end{array}$} \\
\hline & 0.058 & 0.005 & 0.057 & 0.006 & 98.27 & 104.01 & & \\
\hline & 0.061 & 0.005 & 0.060 & 0.005 & 98.36 & 104.01 & & \\
\hline \multirow{3}{*}{$100 \%$} & 0.121 & 0.010 & 0.119 & 0.010 & 99.16 & 98.05 & \multirow{3}{*}{$\begin{array}{l}99.71 \% \\
(1.41 \%)\end{array}$} & \multirow{3}{*}{$\begin{array}{l}98.71 \% \\
(0.47 \%)\end{array}$} \\
\hline & 0.120 & 0.011 & 0.122 & 0.010 & 101.66 & 99.09 & & \\
\hline & 0.120 & 0.010 & 0.118 & 0.009 & 98.33 & 99.00 & & \\
\hline \multirow{3}{*}{$150 \%$} & 0.183 & 0.015 & 0.185 & 0.015 & 101.09 & 102.03 & \multirow{3}{*}{$\begin{array}{l}100.36 \% \\
(1.03 \%)\end{array}$} & \multirow{3}{*}{$\begin{array}{l}99.60 \% \\
(1.73 \%)\end{array}$} \\
\hline & 0.182 & 0.016 & 0.180 & 0.015 & 98.90 & 98.12 & & \\
\hline & 0.181 & 0.015 & 0.183 & 0.014 & 101.10 & 98.66 & & \\
\hline \multicolumn{7}{|c|}{ Mean } & $\begin{array}{l}99.46 \% \\
(0.82 \%)\end{array}$ & $\begin{array}{l}100.35 \% \\
(1.31 \%)\end{array}$ \\
\hline
\end{tabular}




\section{Precision}

The precision of the method was calculated by executing intra-day and interday precision at $100 \%$ concentration $(120 \mu \mathrm{g} / \mathrm{ml}$ of FEX and $10 \mu \mathrm{g} / \mathrm{ml}$ of MON$)$. Six injections of the above solutions were injected into HPLC system at some other time of the same day for intra-day precision. For inter-day precision, $100 \%$ solutions were injected six times by different analyst on different day. The results showed that the \% relative standard deviation (\%RSD) was less than $2 \%$ and are reported in Table 5 .

Table 5. Precision of the proposed method for FEX and MON.

\begin{tabular}{|c|c|c|c|c|c|c|c|c|}
\hline \multirow[t]{2}{*}{ Parameters } & \multicolumn{2}{|c|}{ Amount added (mg) } & \multicolumn{2}{|c|}{ Amount found (mg) } & \multicolumn{2}{|c|}{ Recovery (\%) } & \multicolumn{2}{|c|}{$\begin{array}{l}\text { Mean \% Recovery } \\
\text { (\%RSD) }\end{array}$} \\
\hline & FEX & MON & FEX & MON & FEX & MON & FEX & MON \\
\hline \multirow{6}{*}{$\begin{array}{l}\text { Intra-day } \\
\text { precision }\end{array}$} & 0.120 & 0.011 & 0.118 & 0.010 & 98.33 & 99.09 & \multirow{6}{*}{$\begin{array}{l}99.17 \% \\
(1.27 \%)\end{array}$} & \multirow{6}{*}{$\begin{array}{l}98.92 \% \\
(0.96 \%)\end{array}$} \\
\hline & 0.122 & 0.010 & 0.119 & 0.009 & 97.54 & 98.01 & & \\
\hline & 0.118 & 0.012 & 0.117 & 0.012 & 99.15 & 100.82 & & \\
\hline & 0.123 & 0.011 & 0.124 & 0.011 & 100.81 & 99.14 & & \\
\hline & 0.122 & 0.010 & 0.120 & 0.010 & 98.36 & 98.14 & & \\
\hline & 0.120 & 0.012 & 0.121 & 0.011 & 100.83 & 98.34 & & \\
\hline \multirow{6}{*}{$\begin{array}{l}\text { Inter-day } \\
\text { precision }\end{array}$} & 0.123 & 0.010 & 0.125 & 0.011 & 101.62 & 101.85 & \multirow{6}{*}{$\begin{array}{r}101.10 \% \\
(0.91 \%)\end{array}$} & \multirow{6}{*}{$\begin{array}{l}100.45 \% \\
(1.27 \%)\end{array}$} \\
\hline & 0.117 & 0.012 & 0.119 & 0.012 & 101.70 & 101.62 & & \\
\hline & 0.120 & 0.010 & 0.121 & 0.010 & 100.83 & 100.94 & & \\
\hline & 0.121 & 0.012 & 0.123 & 0.012 & 101.65 & 100.80 & & \\
\hline & 0.120 & 0.011 & 0.119 & 0.011 & 99.16 & 99.15 & & \\
\hline & 0.120 & 0.012 & 0.122 & 0.012 & 101.66 & 98.37 & & \\
\hline \multicolumn{7}{|c|}{ Mean } & $\begin{array}{l}100.14 \% \\
(1.09 \%)\end{array}$ & $\begin{array}{l}99.68 \% \\
(1.12 \%)\end{array}$ \\
\hline
\end{tabular}

\section{Robustness}

Robustness was calculated by making intentional small changes in the parameters of assay method. It was checked by changes in flow rate $( \pm 0.2 \mathrm{ml} / \mathrm{min})$ and wavelength $( \pm 2 \mathrm{~nm})$. The results are reported in Table 6 and it is shown that the intentional changes do not affect the method. 
Table 6. Robustness of the proposed method for FEX and MON.

\begin{tabular}{|c|c|c|c|c|}
\hline \multirow{2}{*}{$\begin{array}{l}\text { Variation para- } \\
\text { meters }\end{array}$} & \multicolumn{2}{|c|}{ Accuracy $\%^{\mathrm{a}} \pm \mathrm{SD}$} & \multicolumn{2}{|c|}{ Relative Standard Deviation (\%RSD) } \\
\hline & FEX & MON & FEX & MON \\
\hline \multicolumn{5}{|c|}{ Flow rate $( \pm 0.2 \mathrm{ml} / \mathrm{min})$} \\
\hline $1.3 \mathrm{ml} / \mathrm{min}$ & $101.82 \pm 1.4$ & $101.04 \pm 0.8$ & $0.86 \%$ & $0.49 \%$ \\
\hline $1.7 \mathrm{ml} / \mathrm{min}$ & $100.49 \pm 1.6$ & $99.57 \pm 1.7$ & $0.73 \%$ & $0.74 \%$ \\
\hline \multicolumn{5}{|l|}{ Wavelength $( \pm 2 \mathrm{~nm})$} \\
\hline $252 \mathrm{~nm}$ & $103.34 \pm 1.8$ & $106.11 \pm 1.5$ & $0.87 \%$ & $0.68 \%$ \\
\hline $256 \mathrm{~nm}$ & $101.61 \pm 1.2$ & $101.17 \pm 0.8$ & $0.63 \%$ & $0.66 \%$ \\
\hline
\end{tabular}

\section{Specificity}

Specificity is the capacity of the method to determine univocally the analyte in the sample in presence of excipients, impurities and degradation products. In present study specificity study was conducted by the forced degradation of the analyte molecule. All the samples were exposed to stress conditions such as acid hydrolysis, alkaline hydrolysis, thermal degradation, oxidative degradation and photolysis for about 2 hours. The results are reported in Table7 with \% of degradation and recovery of analyte with peak purity. The forced degradation chromatograms are featured in Figure4-8. Though various unknown peaks, placebo peaks and a blank peak appeared in the chromatogram, the peak purity values show that the degraded products do not affect the purity of principle peaks of both analytes. Unknown peak 1 was found to be Fexofenadine related compound A with reference to the spectral index results of Radhakrishna and co-workers. ${ }^{69}$

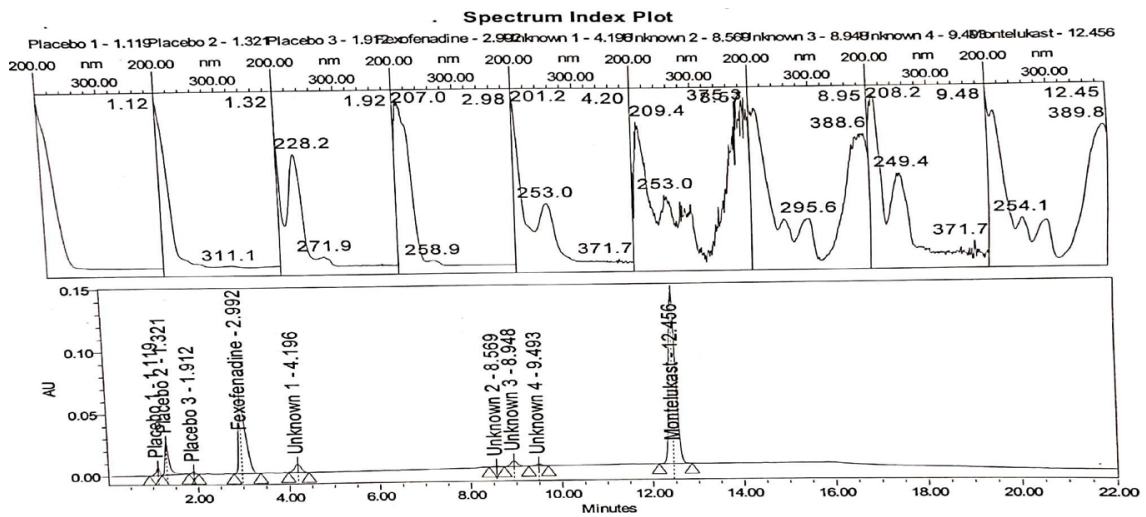

Figure 4. Chromatogram after acid degradation. 
Spectrum Index Plot

Blank- 1.136 Placebo - 1.317 Fexofenadine - 2.974 Unknown 1 - 4.169 Unknown 2 - 8.516 Unknown 3 - 8.922 Unknown 4 - 9.799Montelukast - 14.295
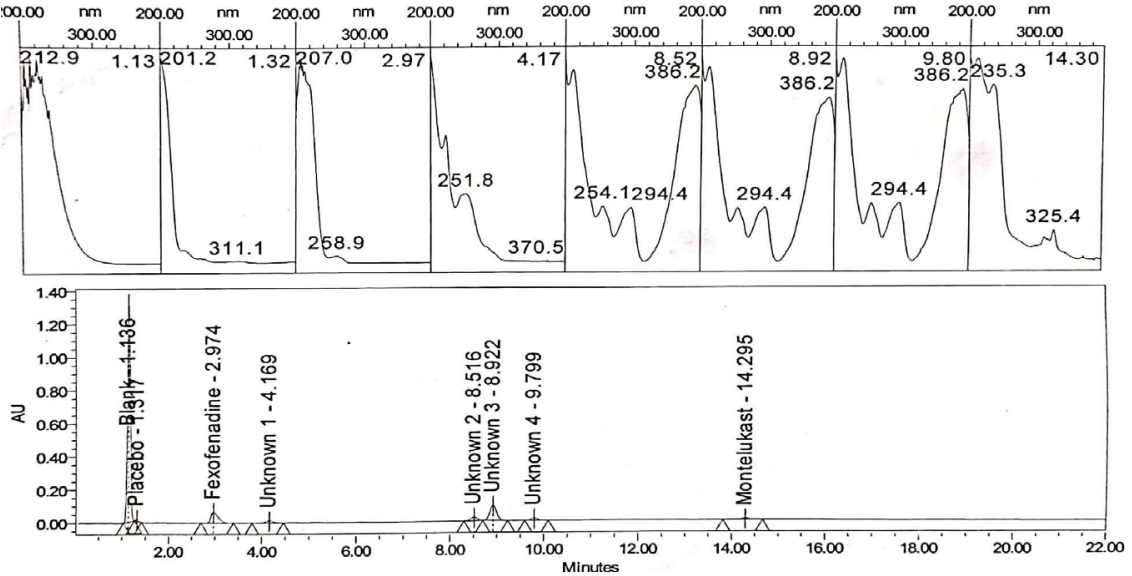

Figure 5.Chromatogram after alkaline degradation.

\section{Spectrum Index Plot}

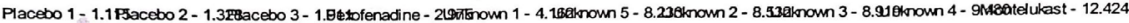
$0.00 \mathrm{~nm} 200.00 \mathrm{~nm} 200.00 \mathrm{~nm} 200.00 \mathrm{~nm} 200.00 \mathrm{~nm} \quad 200.00 \mathrm{~nm} \quad 200.00 \mathrm{~nm} \quad 200.00 \mathrm{~nm} \quad 200.00 \quad \mathrm{~nm} \quad 200.00 \mathrm{~nm}$
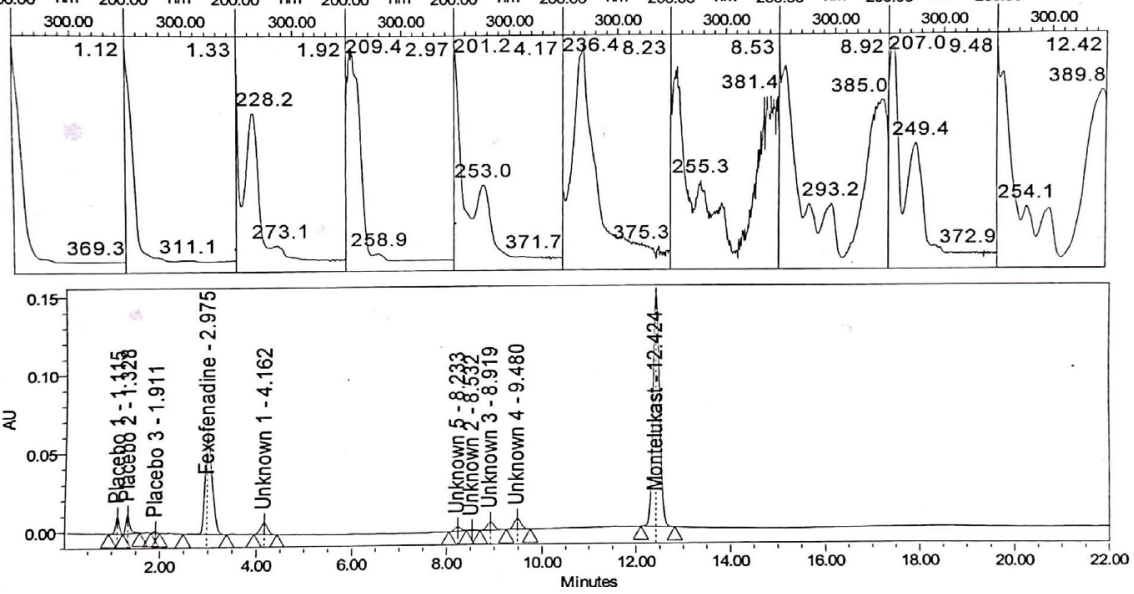

Figure 6.Chromatogram after Oxidative degradation. 
Spectrum Indox rlot

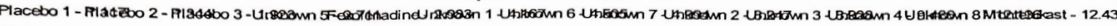
$200.00 \mathrm{~mm} 200.00 \mathrm{~nm} 200.00 \mathrm{~mm} 200.00 \mathrm{~nm} 200.00 \mathrm{~nm} 200.00 \mathrm{~nm} 200.00 \mathrm{~nm} 200.00 \mathrm{~nm} 200.00 \mathrm{~nm} 200.00 \mathrm{rm} 200.00 \mathrm{~nm} 200.00 \mathrm{~nm} 200.00 \mathrm{~nm}$
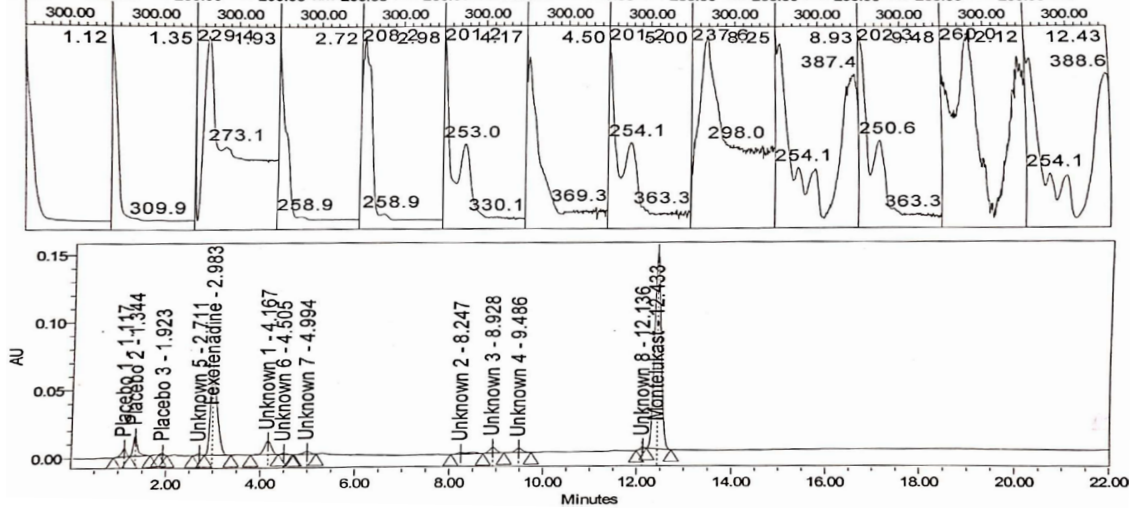

Figure 7.Chromatogram after Photolytic degradation.

Spectrum Index Plot

Blank- 1.136 Placebo - 1.317 Fexofenadine - 2.974Unknown 1 - 4.169 Unknown 2 - 8.516 Unknown 3 - 8.922 Unknown 4 - 9.799Montelukast - 14.295

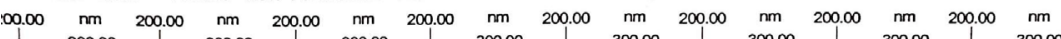
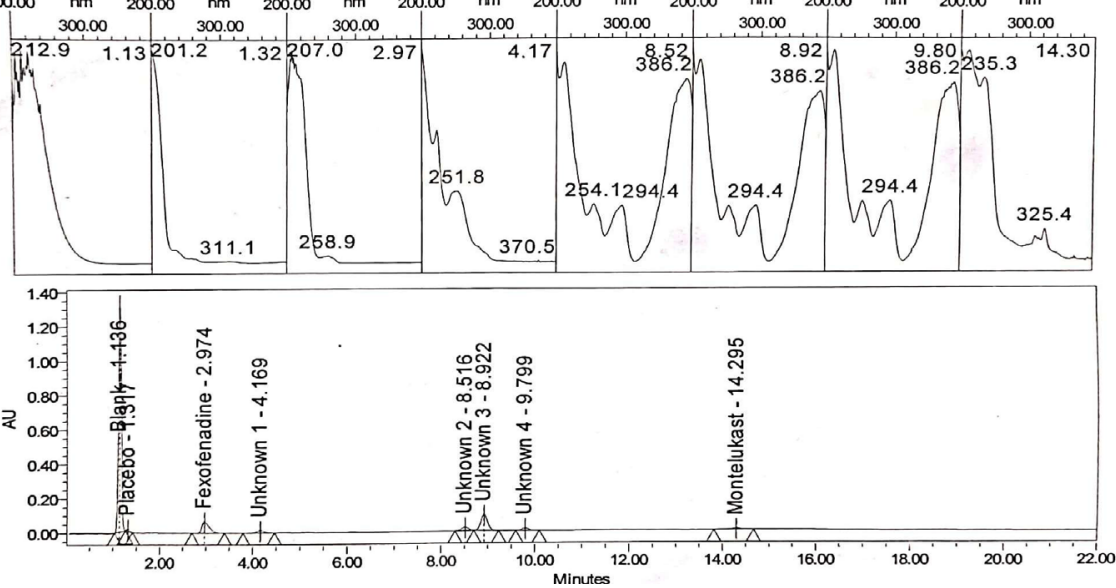

Figure 8.Chromatogram after Thermal degradation.

Table 7. Specifity of the proposed method FEX and MON after forced degradation.

\begin{tabular}{|c|c|c|c|c|c|c|c|c|}
\hline \multirow{2}{*}{$\begin{array}{c}\text { Degradation } \\
\text { condition }\end{array}$} & \multicolumn{2}{|c|}{ Recovery \% } & \multicolumn{2}{c|}{ Degradation \% } & \multicolumn{2}{c|}{ Peak purity } & \multicolumn{2}{c|}{ Threshold purity } \\
\cline { 2 - 9 } & FEX & MON & FEX & MON & FEX & MON & FEX & MON \\
\hline Acid & 92.50 & 88.05 & 7.50 & 11.95 & 0.879 & 0.585 & 1.125 & 0.712 \\
\hline Alkali & 94.70 & 96.20 & 5.30 & 3.80 & 0.778 & 0.545 & 1.058 & 0.705 \\
\hline Oxidative & 86.50 & 91.30 & 13.50 & 8.70 & 0.895 & 0.515 & 1.180 & 0.762 \\
\hline Thermal & 96.70 & 97.20 & 3.30 & 2.80 & 0.775 & 0.543 & 1.111 & 0.722 \\
\hline Photolysis & 97.20 & 84.66 & 2.80 & 15.34 & 0.787 & 0.589 & 1.021 & 0.798 \\
\hline
\end{tabular}


Gampa vijaya kumar and co-workers ${ }^{33}$ did not observe any additional peaks in the chromatogram of degraded FEX and MON. In the present study FEXhighly degraded in oxidative degradation condition (30\% hydrogen peroxide solution) as similar to Maher and Co-partner work ${ }^{29}$. Rameezuddin and collaborators ${ }^{34}$ reported a very less oxidative degradation of $5.3 \%$ due to the usage of $3 \%$ hydrogen peroxide solution for FEX.Rajeev kumar and confederates ${ }^{35}$ did not observe any supplementary peaks in the chromatogram of degradation whereasin the same degradation conditions unknown additional peaks were observed in the chromatogram of present study. Montelukast sodium is highly degraded in photolytic degradation study which is showing a similar response like the report of Juliana roman and co-partners ${ }^{32}$. The reason for high photo-degradation is that MON is a photosensitive compound ${ }^{70}$

\section{Solution stability}

Solution stability is the stability of standard and sample solutions which are injected into the HPLC system. The solvent used for sample solution has chances to decompose the chemical compound during sample preparation process. Normally, a degradation of $2 \%$ is allowed for solution stability from its initial condition ${ }^{71}$. Both the standard and sample solutions were found to be stable up to 25 hours.

\section{Filter integrity}

Filter integrity study is used to determine that the filters are used for the intended purpose and does not interfere in analysis. Filters such as nylon membrane, Teflon, Polyvinylidene fluoride, Polytetrafluoroethylene membrane filters were used during the sample preparation. None of the above filters used were found to interfere with study. Results are reported in Table8

A simple, rapid, precise stability indicating assay method using RP-HPLC for the determination of FEX and MONin tablet dosage form was developed. The proposed method was validated according to $\mathrm{ICH}$ guidelines with the validation parameters such as accuracy, precision, robustness, intra-day , inter-day precision and specificity. The percentage degradation was within the limit for commercial tablets and the degraded peaks do not interfere with significant main peaks. The proposed method can be used for routine analysis and quality control analysis of pharmaceutical preparations. The identification of unknown impurity peaks may be taken up as further research in this study. 
Table 8. Filter integrity of the method.

\begin{tabular}{|c|c|c|c|}
\hline \multirow{2}{*}{ S.No } & Filter Integrity & \multicolumn{2}{|c|}{$\%$ Deviation from the initial area } \\
\cline { 3 - 4 } & & FEX & MON \\
\hline $\mathbf{1}$ & Centrifuge & - & - \\
\hline $\mathbf{2}$ & PVDF $0.45 \mu \mathrm{m}$ (Polyvinylidene fluoride) & 2.40 & 0.84 \\
\hline $\mathbf{3}$ & Nylon $0.45 \mu \mathrm{m}$ & 2.33 & 1.23 \\
\hline $\mathbf{4}$ & PTFE $0.45 \mu \mathrm{m}$ (Polytetrafluoroethylene) & 2.73 & 1.29 \\
\hline
\end{tabular}

\section{CONFLICT OF INTEREST}

The authors declare no conflict of interest.

\section{ACKNOWLEDGEMENT}

The authors are thankful to C. L. Baid Metha College of Pharmacy for the support and encouragement and M/S Sai Mirra Innopharm Pvt. Ltd., Chennai, Tamilnadu for providing the facilities for doing the research work. 


\section{REFERENCES}

1. Montvale, N.J. (2006). Thomson PDR The Physicians' desk reference, $60^{\text {th }}$ ed. Florence.

2. Bachert, C. (2009). A review of the efficacy of desloratadine, fexofenadine, and levocetirizine in the treatment of nasal congestion in patients with allergic rhinitis. Clinical therapeutics, 31(5), 921-944.

3. Compalati, E., Baena-Cagnani, R., Penagos, M., Badellino, H., Braido, F., Gómez, R. M., ... \& Baena-Cagnani, C. E. (2011). Systematic review on the efficacy of fexofenadine in seasonal allergic rhinitis: a meta-analysis of randomized, double-blind, placebo-controlled clinical trials. International archives of allergy and immunology, 156(1), 1-15.

4. Sweetman, S. C. (2009). Martindale: the complete drug reference. Pharmaceutical press.

5. Scott, J. P., \& Peters-Golden, M. (2013). Antileukotriene agents for the treatment of lung disease. American journal of respiratory and critical care medicine, 188(5), 538-544.

6. Nalini, C. N., Vinoth, G., \& Guganathan, P. Investigating (2021). the stress effects on Fexofenadine hydrochloride and Montelukast sodium in bulk and tablet dosage form using a validated LC-DAD method. Unpublished work.

7. Rele Rajan, V., Sawant Swapnil, A. (2013). A non-aqueous potentiometric titration method for quantitative determination of Fexofenadine form pharmaceutical preparation.J. Chem. Pharm. Res. 5, 286-289.

8. Safwan,A., Mouhammed, K., Ruba Mahrouesh. (2013). Extractive spectrophotometric and conductometric methods for determination of Fexofenadine Hydrochloride in pharmaceutical dosage forms. Pharmaceutica Analytica Acta. 82, 01-06.

9. Narayana, B., \& Veena, K. (2010). A new method for the spectrophotometric determination of fexofenadine hydrochloride.

10. Raghubabu, K., \& Sanadhyarani, K. (2014). Assay of Fexofenadine hydrochloride in pharmaceutical preparation by visible spectrophotometry. Der Pharma Chemica, 6(1), 436-439.

11. Polawar, P. V., Shivhare, U. D., Bhusari, K. P., \& Mathur, V. B. (20o8). Development and validation of spectrophotometric method of analysis for fexofenadine $\mathrm{HCl}$. Research Journal of Pharmacy and Technology, 1(4), 539-540.

12. Kumar, K. S., Ravich, V., Raja, M. M. M., Thyagu, R., \& Dharamsi, A. (2006). Spectrophotometric determination of Fexofenadine hydrochloride. Indian Journal of Pharmaceutical Sciences, 68(6).

13. Kumar, J. V., Ramachandran, D., Sushma, K., \& Vijay, S. (2010). Visible spectrophotometric methods for estimation of montelukast sodium in bulk dosage forms and formulations. Orient J Chem, 26, 293-6.

14. Breier, A. R., Steppe, M., \& Schapoval, E. E. S. (2007). Validation of UV spectrophotometric method for fexofenadine hydrochloride in pharmaceutical formulations and comparison with HPLC. Analytical letters, 4O(12), 2329-2337.

15. Dobariya Chandrika, T., Bhumika Patel, R., Zarna Dedania, R., \& Vijendraswamy, S. M. (2015). UV Spectrophotometric method development and validation for Fexofenadine Hydrochloride in bulk and tablet dosage form. J. Pharma Res, 4, 63-68.

16. Raghu, M. S., Shantharam, C. S., \& Yogesh Kumar, K. (2018). Application of BromateBromide Mixture as a Green Brominating Agent for the Determination of Fexofenadine Hydro- 
chloride Pharmaceutical Dosage Form. J. Anal. Pharm. Res, 7, 13-21.

17. Chaudhary, M., Kumar, P., \& Thapliyal, D. (2018). Analytical method development and validation for determination of Montelukast by UV-spectroscopy in API and in pharmaceutical dosage forms. Int. J. Pharm. Bio. Sci, 4, 482-487.

18. Pallavi, K., \& Babu, S. (2012). Validated UV Spectroscopic method for estimation of Montelukast sodium from bulk and tablet formulations. International Journal of Advances in Pharmacy, Biology and Chemistry, 1(4).

19. Kothapalli, P L., Mahajan, A. G., Thomas, A. B., Nanda, R. K.; Narnaware. S. (2012). Simultaneous spectrophotometric estimation of Fexofenadine Hydrochloride and Montelukast sodium in pharmaceutical dosage form. Int. J. Institution Pharm. Life Sci. 2, 72-80.

20. Patle, D., \& Nagar, S. (2017). UV-visible spectrophotometric estimation of montelukast and fexofenadine by simultaneous equation method in bulk \& combined tablet dosage form. Curr Trends Biotechnol Pharm, 11(4), 382-388.

21. Vekaria, H. J., Muralikrsihna, K. S., Patel, G. F. (2011). Development and validation of spectrophotometric method for estimation of Fexofenadine hydrochloride and Montelukast sodium in combined dosage form. Inventi Impact: Pharm Analysis \& Quality Assurance. 15, 2-9. 22. Kozan, I., Palabiyik, I. M., Karacan, E., \& Onur, F. (20o8). Spectrophotometric and high performance liquid chromatographic determination of fexofenadine hydrochloride in pharmaceutical formulations. Turkish Journal of Pharmaceutical Sciences, 5(3), 175-189.

23. Alothman, Z. A., Bukhari, N., Haider, S., Wabaidur, S. M., \& Alwarthan, A. A. (2010). Spectrofluorimetric determination of fexofenadine hydrochloride in pharmaceutical preparation using silver nanoparticles. Arabian Journal of Chemistry, 3(4), 251-255.

24. Alsarra, I., Khalil, N. Y., Sultan, M., Al-Ashban, R., \& Belal, F. (2005). Spectrofluorometric determination of montelukast in dosage forms and spiked human plasma. Die Pharmazie-An International Journal of Pharmaceutical Sciences, 6o(11), 823-826.

25. Al-Kindy Salma, M. Z., Khadija AI-Shamalani, Fakhr Eldin, Suliman, O., Haidar AI-Lawati, H. J. (2011). Terbium sensitized luminescence for the determination of Fexofenadine in pharmaceutical formulations.Arabian J Chem. 8, 1-15.

26. Pallavi, M., Deepali, A., Bansode \& Suneela, Dhaneshwar, S. (2015). Stability indicating thin-layer chromatographic determination of Fexofenadine hydrochloride as bulk drug: application to forced degradation study. Der Pharmacia Sinica. 6, 30-39.

27. Athavia, B. A., Dedania, Z. R., Dedania, R. R., Vijayendra Swamy, S. M., Chandrika Dobariya, T. (2017). Stability indicating HPTLC method development for Fexofenadine Hydrochloride.European J Biomed Pharm Sci. 4, 697-705.

28. Tandulwadkar, S. S., More, S. J., Rathore, A. S., Nikam, A. R., Sathiyanarayanan, L., \& Mahadik, K. R. (2012). Method development and validation for the simultaneous determination of fexofenadine hydrochloride and montelukast sodium in drug formulation using normal phase high-performance thin-layer chromatography. International Scholarly Research Notices, 2012.

29. Maher, H. M., Sultan, M. A., \& Olah, I. V. (2011). Development of validated stability-indicating chromatographic method for the determination of fexofenadine hydrochloride and its related impurities in pharmaceutical tablets. Chemistry Central Journal, 5(1), 1-10.

3o. Nimje, H. M., Nimje, S. T., Oswal, R. J., \& Bhamre, S. T. (2012). Stability indicating RP- 
HPLC method for estimation of fexofenadine hydrochloride in pharmaceutical formulation. $E$ Journal of Chemistry, 9(3), 1257-1265.

31. Patnaik, A., Panda, S. S., Sahoo, S., \& Patro, V. J. (2012). RP-HPLC method development and validation for the determination and stability indicative studies of Montelukast in bulk and its pharmaceutical formulations. E-Journal of Chemistry, 9(1), 35-42.

32. Roman, J., Breier, A. R., \& Steppe, M. (2011). Stability indicating LC method to determination of sodium montelukast in pharmaceutical dosage form and its photodegradation kinetics. Journal of chromatographic science, 49(7), 540-546.

33. Gampa Vijaya, K., Rajesh, T., Jaya Chandra, T. A. (2018). Stability indicating RP-HPLC method development and validation for simultaneous estimation of Montelukast sodium and Fexofenadine Hydrochloride in bulk and pharmaceutical dosage form. Indo Am. J. P. Sci. 5, 16756-16765.

34. Rameezuddin, M. D., Vasanth, P. M., Ramesh, T., Ramesh, M. (2013). Method development and stability indicating RP-HPLC method for the estimation of Montelukast and Fexofenadine for bulk and pharmaceutical dosage form.Int.J.ChemTech Res. 5, 2821-2829.

35. Rajeev Kumar, P., \& Kumar, R. R. (2017). Validated stability-indicating isocratic RP-HPLC method of estimation of Montelukast sodium and Fexofenadine hydrochloride in bulk and in solid dosage by vierodt's method. J. Chem. Pharm. Res, 9, 297-243.

36. Pankhaniya, M., Patel, P., \& Shah, J. S. (2013). Stability-indicating HPLC method for simultaneous determination of montelukast and fexofenadine hydrochloride. Indian journal of pharmaceutical sciences, 75(3), 284.

37. Padmavaathi, K., \& Rao, S. (2015). M. A new stability-indicating RP-HPLC method for the simultaneous determination of Fexofenadine hydrochloride and Montelukast in combined dosage form. Der Pharmacia Lettre, 7, 301-307.

38. Oliveira, D. C., Weich, A., \& Rolim, C. M. B. (2007). Simple and reliable HPLC analysis of fexofenadine hydrochloride in tablets and its application to dissolution studies. Die PharmazieAn International Journal of Pharmaceutical Sciences, 62(2), 96-100.

39. Breier, A. R., Paim, C. S., Steppe, M., \& Schapoval, E. E. (2005). Development and validation of dissolution tests for fexofenadine hydrochloride capsules and coated tablets. J Pharm Pharm Sci, 8(2), 289-298.

40. Rele, R. V. (2016). Determination of fexofenadine hydrochloride in pharmaceutical dosage form by reverse phase high performance liquid chromatography method. Der Pharma Chem, 8(6), 224-228.

41. Sakalgaonkar, A. A., Mirgane, S. R., \& Pawar, R. P. (20o8). Validated LC method, with a chiral mobile phase, for separation of the isomers of Fexofenadine hydrochloride. Chromatographia, 68(1), 143-146.

42. Wang, D., Zhou, C., Cong, R., Li, Y., \& Wang, X. (2017). Simultaneous determination of Montelukast sodium S-enantiomer and A5 enantiomers in Montelukast sodium bulk drug by normal-phase chiral HPLC. Indian Journal of Pharmaceutical Sciences, 79(1), 139-148.

43. Singh, R. M., Saini, P. K., Mathur, S. C., Singh, G. N., \& Lal, B. (2010). Development and validation of a RP-HPLC method for estimation of montelukast sodium in bulk and in tablet dosage form. Indian journal of pharmaceutical sciences, 72(2), 235.

44. Devi, K. K. D., Rani, A. P., Madhavi, B. R., \& Mrudula, B. S. (2010). New RP-HPLC meth- 
od for the analysis of montelukast sodium in pharmaceutical dosage form. Int. J. Chem Tech Res, 2(1), 471-75.

45. Phadtare, D. G., Pawar, A. R., Kulkarni, R. R., \& Patil, G. K. (2016). Method development and validation of Montelukast sodium in bulk and tablet formulation by HPLC. Tablet, 2(80), 99-14.

46. Priyanka, D., Sireesha, M., Akiful Haque, S., \& Harshini, V. B. (2014). Method development and validation of Fexofenadine hydrochloride and Montelukast sodium in a combined dosage form by RP-HPLC method. Int J Med Nanotechnolo, 1, 174-178.

47. Tamilselvi, N., \& Sruthi, K. (2012). Development of validated HPLC method for simultaneous estimation of Fexofenadine hydrochloride and Montelukast sodium in tablet dosage form. International Journal of Pharmaceutical Sciences and Research, 3(12), 4876.

48. Lakshmi, Y. M., Srinivasa, R., Meghana, R. (2013). Method development and validation for simultaneous estimation of Fexofenadine $\mathrm{HCl}$ and Montelukast Sodium by RP-HPLC in pure and combined tablet dosage form. World J Pharm Pharm Sci. 2, 5948-5965.

49. Ravisankar, M., Uthirapathy, S., Thangadurai, A., \& Dhanapal, K. (2012). simultaneous estimation of fexofenadine hydrocloride and montelukast sodium in bulk drug and marketed formulation by RP-HPLC method. Int Res J Pharm, 3, 356-9.

50. Tukaram, M. K., Risha, R. W., \& Rajendra, B. K. (2013). Development and validation of RP-HPLC method for estimation of montelukast sodium and fexofenadine hydrochloride in pharmaceutical preparations. Chemical Science Transactions, 2(3), 889-899.

51. Swarnalatha, G., Vijayakumar, B., Jothieswari, D., Poojitha, M., Ravi Chandrakumar, A., Gobala Krishnan, P. (2016). RP-HPLC Method development and validation for simultaneous estimation of Montelukast sodium and Fexofenadine $\mathrm{HCl}$ in a pharmaceutical dosage form. Int J Med Chem Anal. 6, 44-51.

52. Arayne, M. S., Sultana, N., Shehnaz, H., \& Haider, A. (2011). RP-HPLC method for the quantitative determination of fexofenadine hydrochloride in coated tablets and human serum. Medicinal chemistry research, 20(1), 55-61.

53. Uno, T., Yasui-Furukori, N., Takahata, T., Sugawara, K., \& Tateishi, T. (2004). Liquid chromatographic determination of fexofenadine in human plasma with fluorescence detection. Journal of pharmaceutical and biomedical analysis, 35(4), 937-942.

54. Al-Rawithi, S., Al-Gazlan, S., Al-Ahmadi, W., Alshowaier, I. A., Yusuf, A., \& Raines, D. A. (2001). Expedient liquid chromatographic method with fluorescence detection for montelukast sodium in micro-samples of plasma. Journal of Chromatography B: Biomedical Sciences and Applications, 754(2), 527-531.

55. Ochiai, H., Uchiyama, N., Takano, T., Hara, K. I., \& Kamei, T. (1998). Determination of montelukast sodium in human plasma by column-switching high-performance liquid chromatography with fluorescence detection. Journal of Chromatography B: Biomedical Sciences and Applications, 713(2), 409-414.

56. Liu, L., Cheng, H., Zhao, J. J., \& Rogers, J. D. (1997). Determination of montelukast (MK0476) and its S-enantiomer in human plasma by stereoselective high-performance liquid chromatography with column-switching. Journal of pharmaceutical and biomedical analysis, 15(5), 631-638.

57. Vaghela, B., Rao, S. S., Reddy, A. M., Venkatesh, P., \& Kumar, N. (2012). Identification and 
characterization of an oxidative degradation product of fexofenadine, development and validation of a stability-indicating RP-UPLC method for the estimation of process related impurities and degradation products of fexofenadine in pharmaceutical formulations. Scientia pharmaceutica, $80(2)$, 295-310.

58. Mangamma, K., \& Dannana, G. S. (2017). Stability-indicating UPLC method for estimation of Montelukast and Fexofenadine simultaneously in the presence of stress degradation products. J Global Trends Pharm Sci, 8, 4542-4553.

59. Stanton, M. L., Joy, M. S., Frye, R. F. (2010). Validation and application of a liquid chromatography-tandem mass spectrometric method for quantification of the drug transport probe Fexofenadine in human plasma using 96-well filter plates. $J$ Chromatogr B. 878 1-11.

6o. Hofmann, U., Seiler, M., Drescher, S., \& Fromm, M. F. (2002). Determination of fexofenadine in human plasma and urine by liquid chromatography-mass spectrometry. Journal of Chromatography B, 766(2), 227-233.

61. Jo, M. H., Park, M. S., Seo, J. H., Shim, W. S., Yim, S. V., \& Lee, K. T. (2011). Pharmacokinetic analysis of montelukast in healthy Korean volunteers by high performance liquid chromatography-tandem mass spectrometry. Journal of Pharmaceutical Investigation, 41(5), 289-294.

62. Mikuš, P., Valášková, I., \& Havránek, E. (2005). Determination of fexofenadine in tablets by capillary electrophoresis in free solution and in solution with cyclodextrins as analyte carriers. Drug development and industrial pharmacy, 31(8), 795-801.

63. United States Pharmacopeia. (2009). Monograph on Fexofenadine hydrochloride Tablets, America.

64. United States Pharmacopeia. (2010). Monograph on Montelukast sodium Tablets, America.

65. Long, W., Henderson, J. W., \& Joseph, M. (2008). Comparing selectivity of phenylhexyl and other types of phenyl bonded phases. LC GC North America, (JUN), 49-49.

66. Bhal, S. K. (2007). LogP-making sense of the value. Advanced chemistry development, Toronto, ON, Canada, 1-4.

67. ICH. (2003). Stability Testing of New drug substances and Products, International Conferenceon Harmonization, Geneva.

68. ICH. (2005). Q2 (R1) Validation of Analytical Procedures: Text and Methodology International Conferenceon Harmonization of Technical Requirements for Registration ofPharmaceuticals for Human Use, Geneva.

69. Radhakrishna, T., \& Reddy, G. O. (2002). Simultaneous determination of fexofenadine and its related compounds by HPLC. Journal of pharmaceutical and biomedical analysis, 29(4), 681-690.

70. Al Omari, M. M., Zoubi, R. M., Hasan, E. I., Khader, T. Z., \& Badwan, A. A. (2007). Effect of light and heat on the stability of montelukast in solution and in its solid state. Journal of pharmaceutical and biomedical analysis, 45(3), 465-471.

71. Ahuja, S., \& Dong, M. (Eds.). (2005). Handbook of pharmaceutical analysis by HPLC. Elsevier. 